\title{
Prediction of Wax Precipitation Temperature in Petroleum Fluids
}

\section{Onyejekwe Ifeanyichukwu Michael, Duru Ugochukwu Ilozuruike, Obibuike Ubanozie Julian, Uwaezuoke Nnaemeka}

Department of Petroleum Engineering, Federal University of Technology, Owerri, Nigeria

Email address:

oronst@yahoo.com (O. I. Michael)

${ }^{*}$ Corresponding author

\section{To cite this article:}

Onyejekwe Ifeanyichukwu Michael, Duru Ugochukwu Ilozuruike, Obibuike Ubanozie Julian, Uwaezuoke Nnaemeka. Prediction of Wax Precipitation Temperature in Petroleum Fluids. International Journal of Oil, Gas and Coal Engineering. Vol. 9, No. 1, 2021 , pp. 6-11. doi: 10.11648/j.ogce.20210901.12

Received: January 12, 2021; Accepted: February 15, 2021; Published: March 4, 2021

\begin{abstract}
The precipitation and deposition of wax has remained a major challenge that the oil industries is faced with during the production of waxy crude. This problem is simply an issue from the wellbore to the surface facilities. As a result of this, millions of dollars has been invested in remedial operations. In this research, a predictive model that uses thermodynamic relationship in predicting precipitation of wax has been developed. K-values for the solid-liquid equilibrium is described using solubility parameter, melting point temperature, enthalpy of fusion, and the molar volume for the components. The weight fraction was used to describe the wax mixture. Experimental data from three oil mixtures were used in comparing the model predicted wax appearance temperature (WAT). For oil mixA, the experimental value is $294.15 \mathrm{~K}$; Pauly et al predicted $302.15 \mathrm{~K}$ while this work predicted $301.21 \mathrm{~K}$. For oil mixB, the experimental value is $300.15 \mathrm{~K}$; Pauly et al predicted $310.15 \mathrm{~K}$ while this work predicted $308.91 \mathrm{~K}$. For oil mixC, the experimental value is $298.15 \mathrm{~K}$; Pauly et al predicted $302.15 \mathrm{~K}$ while this work predicted $300.38 \mathrm{~K}$. The obtained results from this research confirmed the capability of the model in predicting Wax Appearance Temperature. A more conservative value for the WAT was predicted which is an improvement.
\end{abstract}

Keywords: Thermodynamic Model, Wax Appearance Temperature, Phase Equilibrium, Flash Calculation, Wax Deposition

\section{Introduction}

The evaporation of volatile light end or drop in the system temperature is key to the precipitation of paraffin deposits in crude oils. When reservoir fluids that contains gas flows through bends in pipeline or tubings there is bound to be temperature drop due to Jo Thompson effects. Reactive or curative measures rather than preventive have been the method of approach in solving wax precipitation and deposition problem in the past by operators. For the oil industry, the question of knowing "when" and "how much" of the heavy organic that will flocculate out at a given condition of temperature and pressure has remain their major concern and challenge. In order to address the safety, operational, and design of wax remediation systems, a fundamental understanding of the deposition behaviour of waxy crude is required. The groundbreaking research into the phenomenon of wax deposition is the application of fundamental science to model waxy-oil fluid systems, thus elucidating the controlling physical mechanisms of wax deposition and gel behaviour [1]. As a result of changes in temperature, pressure and composition we have the formation of vapour, liquid and solid phases due to the wide volatility and melting point range of hydrocarbon component found in petroleum. The precipitation of the heavy hydrocarbon components as wax crystals in the liquid and vapour phases is attributed to a drop in temperature. The development of thermodynamic model in describing wax precipitation and deposition is the recent attempts in solving the old problem of wax precipitation.

The results obtained from available methods adopted in predicting wax precipitation are often in poor agreement with observed experimental data, as they attempt to overestimate the amount of wax formed at temperature below the wax appearance temperature. This study is designed to predict the wax appearance temperature through the application of thermodynamic relationship. 


\subsection{Literature Review}

In predicting wax precipitations in crude oils, using thermodynamic relations, researchers has suggested the use of compositional methods that uses regular solution theory of mixtures with equation of state. These methods supposes that the entire compounds that precipitate from the liquid or vapour phase form a solid-solution [2-4]. Though results from the studies on spectroscopic and calorimetric by Snyder et al. [5-7] as well as W. B. Pedersen et al. [8] recommends that large hydrocarbons are equally insoluble in the solid state.

Paraffin waxes deposition problems occur throughout during production and is more pronounced in the tubing strings, chokes, flowlines and separators. Production and design engineers are usually troubled with the buildup of wax on pipe walls and other surfaces. The process of deposition is generally slow with total blockage been rare. Nevertheless, a slight reduction in diameter and more significantly, an increased pipe wall roughness strongly affects the flowline or well performance. Furthermore, wax crystals deposition often results in constant tripping of the export pumps, and decreased pump performance.

Temperature drop below the wax appearance temperature and fluid composition are responsible for wax deposition resulting from changes in the equilibrium condition of the oil mixtures [9]. The limiting factor or difficulty associated with the development of deep sub-sea reservoirs is that of precipitation and deposition of paraffin. Studies $[10,11]$ carried out on wax deposition reviews that deposition of wax crystals will occur on pipe wall and/or transport with fluids. Equipment seizure, pipeline plugging and reduce flowability will result from this action with its attendant costly downtime and expensive remediation technique Anand and Anirbid [12] carried out a review work on the need for flow assurance for crude oil pipelines with special emphasis on wax deposition. They concluded from the result of their finding that crystallization of wax in crude oil is responsible for pressure losses, high yield stress for restarting resulting from high viscosity of crude oil, frequent pipeline shut down and deposition of wax crystallites on various surfaces. Deposition of wax is critical if it results to formation damage during production which could occur when the temperature of the fluid in the formation drops below the wax appearance temperature. Frequent pigging operation is carried out in the pipeline to prevent the pipeline from getting stuck because of the wax deposits [1].

Ahmed and Mike [13] conducted a study in which they compared paraffin deposition result obtain from the laboratory to field data using samples from four reservoir fluids in the Gulf of Mexico. Their propensities toward deposition of paraffin as a result of temperature or pressure changes were investigated. Investigations $[9,14,15]$ on mechanisms of wax deposits have been carried out by various researchers.

Studies on using thermodynamic models in describing wax deposition process have been carried out by researchers [1620]. Engineering models for calculating oil-wax equilibria have been suggested by researchers $[4,21,22]$. Among the recent models on wax deposition thickness is that presented by Halstensen et al. [23]. Pedersen [24] in his study on prediction of cloud point temperature and amount of wax precipitation presented a model which results agree so well with experimental wax precipitation data. He suggested that it is only part of the $\mathrm{C}_{7+}$ fraction that is capable of forming the wax phase. The propensity to over predict cloud point temperature and amount of precipitated wax below the cloud point temperature was conquered through the use of unrealistic pure components properties.

In the modelling of solid precipitation from oil and gas systems, two thermodynamic explanation models are commonly employ. The approximation of the activity coefficient for the liquid or solid phase is accomplished using both the regular solution $[2,24]$ and polymer solution theory $[4,25]$. Sulaimon et al. [26] in their studies in using a proactive method to predict and prevent wax deposition in production tubing strings for Niger Delta field used a three phase thermodynamic model. With the aid of a developed robust computer algorithm, the model predicted the WAT and generated fluid temperature profiles inside the production tubing strings were WIT can be installed to prevent wax deposition. The result from their study indicates that their model was able to predict and determine the possible wax precipitation point inside the tubing.

\subsection{Summary of Reviewed Literature}

On the issue of cloud point detection, it is often observed that proposed techniques are tested using solutions of one or few n-alkanes to emulate the wax formation in real fluid. This approach is not acceptable since the detection techniques rely on the rate of appearance of crystals or the quantity of solid to detect a new phase. Most techniques perform very well for high rates of precipitation.

For the wax models, a general problem by researchers is a tendency to predict too high cloud point temperature and too large amount of wax formed at temperature below the cloud point. It is likely observed that problems encountered with models from literatures is the seemly fact that all $\mathrm{C}_{7+}$ components are considered to be able to potentially form wax, while in reality this is only the case of minor fractions of $\mathrm{C}_{7+}$ component. The wax forming components seem to consist mainly of the n-paraffins, however they are not, as $\mathrm{C}_{7+}$, isoparaffin and naphthenes, especially the light ones will contribute to the wax phase.

Also due to simplifying assumptions made by researchers, none of these models accounts for all the factors that affect wax precipitation modeling.

\section{Methods}

The use of thermodynamic relationship was central in the formulation of equations used for the wax prediction. Fluid composition data for three (3) different synthetic oil mixtures [27] was used in the evaluation of the developed model with the aid of Matlabsoftware program to allow for the running 
of multiphase flash model. The model predicted result was compared with experimental wax appearance temperature (WAT) data.

\subsection{Thermodynamic Model}

Under the principle of thermodynamic relation, at a fixed temperature and pressure, liquid phase and solid phase may coexist as represented by Equation (1).

$$
f_{i}^{L}=f_{i}^{S}
$$

Where $f_{i}^{L}$ and $f_{i}^{S}$ is the fugacities of the component in the liquid and solid phase respectively. The fugacities are individually defined as follows:

$$
\begin{gathered}
f_{i}^{L}=x_{i} \emptyset_{i}^{L} P \\
f_{i}^{L}=x_{i} \gamma_{i}^{L} f_{i}^{o, L} \\
f_{i}^{S}=w_{i} \gamma_{i}^{S} f_{i}^{o, S}
\end{gathered}
$$

In these equations $x_{i}, w_{i}, \gamma_{i}^{L}, \gamma_{i}^{S}, \emptyset_{i}^{L}, \mathrm{P}, f_{i}^{O, L}$ and $f_{i}^{O, S}$ are liquid phase mole fraction, solid phase mole fraction, activity coefficient for liquid component, activity coefficient for solid component, fugacity coefficient of liquid component, pressure, fugacities at state of reference for the liquid and solid phases respectively. The solid-liquid equilibrium constant, $K_{i}^{S-L}$, can be obtained from equations (1), (3) and (4) as shown in Equation (5) below.

$$
K_{i}^{S-L}=\frac{w_{i}}{x_{i}}=\frac{f_{i}^{S} * f_{i}^{o, L} * \gamma_{i}^{L}}{f_{i}^{l} * f_{i}^{O, S} * \gamma_{i}^{S}}
$$

\subsubsection{Model Development}

In accordance with the principle of thermodynamic relationship for liquid and solid phases at a fixed temperature and pressure as shown earlier according to Eqs.(1) through (5), for this work, $K_{i}^{S-L}$ will be determined based on the bellow assumptions.

Assumptions

a) At low to moderate pressure, the difference between the partial molar volume of liquid and solid is considered small, and is therefore neglected.

b) Heat capacity of fusion difference between two phases is considered insignificant, therefore neglected.

c) The activity coefficient is considered.

The combination of Eqs. (1), (3) and (4) yields $K_{i}^{S-L}$ as:

$$
K_{i}^{S-L}=\frac{w_{i}}{x_{i}}=\left[\frac{\gamma_{i}^{L}}{\gamma_{i}^{S}}\right]\left[\frac{f_{i}^{o L}}{f_{i}^{o S}}\right] \exp \left[\int_{p_{o}}^{p} \frac{\Delta V_{i}}{R T} d p\right]
$$

Where: $\Delta V_{i}=V_{i}^{L}-V_{i}^{S}$

From the right hand side of equation (6), molecular interaction effect is the first term, temperature effect is the second term and effect of pressure is the third term. The exponential term represent pressure dependence and is neglected based on assumption"a". Therefore equation (6) becomes:

$$
K_{i}^{S-L}=\frac{w_{i}}{x_{i}}=\left[\frac{\gamma_{i}^{L}}{\gamma_{i}^{S}}\right]\left[\frac{f_{i}^{O, L}}{f_{i}^{O, S}}\right]
$$

\subsubsection{Fluid Model Fugacity Correlation}

The correlation for the phases standard state fugacity from Equation (6) is as shown in Equation (8)

$$
\ln \left[\frac{f_{i}^{o L}}{f_{i}^{o S}}\right]=\frac{\Delta h_{m, i}}{R T}\left[1-\frac{T}{T_{m, i}}\right]+\frac{\Delta C_{P}}{R}\left[1-\frac{T_{m, i}}{T}+\ln \frac{T_{m, i}}{T}\right](8)
$$

Where $\Delta h_{m, i}, T_{m, i}, \mathrm{R}$ and $\Delta C_{P}$ are heat of melting, melting point temperature, universal gas constant and heat capacity of solute fusion respectively. The heat capacity of fusion term is neglected according to "b" assumption.

Then Equation (6) transforms in to equation (9).

$$
K_{i}^{S L}=\frac{w_{i}}{x_{i}}=\frac{\gamma_{i}^{L}}{\gamma_{i}^{S}} \exp \left[\frac{\Delta H_{m, i}}{R T}\left(1-\frac{T}{T_{m, i}}\right)\right]
$$

\subsection{Models Properties}

\subsubsection{Melting point Temperature and Heat of Melting}

The melting point and heat of melting properties are calculated from Eqs.(10) and (11) according to Coutinho [28]

$$
\begin{gathered}
T_{m, i}=421.63-1936112.63 \exp \left[-7.8945\left(C_{n i}-1\right)^{0.07194}\right] \\
\Delta H_{m, i}=1000\left(3.7791 C_{n i}-12.654\right)
\end{gathered}
$$

Where $C_{n i}$ represent the carbon number. The phase change for normal paraffin below $\mathrm{C} 42$ but greater than $\mathrm{C} 4$ is more complex. They form a rotator phase at the melting temperature. The heat of melting is calculated from Equation (10).

The enthalpy of melting is calculated from Equation (12).

$$
\Delta H_{m, i}=1000\left(-0.00355 C_{n i}^{3}+0.2376 C_{n i}^{2}-3.6209 C_{n i}+\right.
$$

\subsubsection{Solid-Liquid Phase Non-ideality}

The activity coefficient parameter is accounted for. Won [3] assumption for regular solution is used to approximate effect of activity coefficients ratio for the liquid-solid which are calculated from the solubility parameters $\delta_{i}^{L}$ and $\delta_{i}^{S}$ of the individual components.

$$
\begin{aligned}
\ln \gamma_{i}^{L} & =\frac{V_{i}^{L}\left(\bar{\delta}^{L}-\delta_{i}^{L}\right)^{2}}{R T} \\
\ln \gamma_{i}^{S} & =\frac{V_{i}^{S}\left(\bar{\delta}^{S}-\delta_{i}^{S}\right)^{2}}{R T} \\
\bar{\delta}^{L} & =\sum \varphi_{i}^{L} \delta_{i}^{L} \\
\bar{\delta}^{S} & =\sum \varphi_{i}^{S} \delta_{i}^{S} \\
\varphi_{i}^{L} & =\frac{x_{i}^{L} V_{i}^{L}}{\sum x_{i}^{L} V_{i}^{L}} \\
\varphi_{i}^{S} & =\frac{x_{i}^{S} V_{i}^{S}}{\sum x_{i}^{S} V_{i}^{S}}
\end{aligned}
$$

Where $\delta_{i}^{L}, \delta_{i}^{S}, \varphi_{i}^{L}, \varphi_{i}^{S}, \bar{\delta}^{L}$ and $\bar{\delta}^{S}$ represents liquid solubility parameter, solid solubility parameter, component volume fraction for the liquid phase, component volume fraction for the solid phase, mean solubility parameters for the liquid and solid phase respectively. 
Combing Equations (13) - (18), gives Equation (19).

$$
\frac{\delta^{L i}}{\delta^{S i}}=\frac{\gamma_{i}^{L}}{\gamma_{i}^{S}} \exp \left(\frac{V_{i}}{R T}\left(\left(\bar{\delta}^{L}-\delta_{i}^{L}\right)^{2}-\left(\bar{\delta}^{S}-\delta_{i}^{S}\right)^{2}\right)\right)
$$

The molar volume for component $\mathrm{i}$ is estimated according to Equation (18).

$$
V_{i}=\frac{M_{w i}}{0.8155+0.6272 \times 10^{-4} M_{w i}-\frac{13.06}{M_{w i}}}
$$

Liquid and solid phase solubility parameters are calculated as follow:

$$
\begin{aligned}
& \delta_{m}^{L}=7.41+0.519\left(\ln C_{n i}-\ln 7\right) \\
& \delta_{m}^{S}=8.50+5.763\left(\ln C_{n i}-\ln 7\right)
\end{aligned}
$$

\subsection{Multiphase Flash Algorithm}

For a solid-liquid system in equilibrium at a constant temperature $\mathrm{T}$ and pressure $\mathrm{P}$, the two-phase stability calculation scheme is represented as follows:

By definition (i.e the overall material balance)

$$
\begin{gathered}
n=n_{L}+n_{S} \\
Z_{i} n=x_{i} n_{L}+w_{i} n_{S}
\end{gathered}
$$

By definition of mole fraction, we may write

$$
\begin{gathered}
\sum_{i} Z_{i}=1 \\
\sum_{i} x_{i}=1 \\
\sum_{i} w_{i}=1
\end{gathered}
$$

Where $\mathrm{n},, n_{L}$ and $n_{S}$ stand for total moles for the mixture, total liquid and solid moles respectively while $Z_{i}, x_{i}$ and $w_{i}$ represents entire hydrocarbon mole fraction, liquid and solid phase mole fraction respectively. The solution algorithm for the liquid-solid equilibrium is as represented in Eqs.(28) and (29) below:

$$
\begin{aligned}
& \sum_{i} x_{i}=\sum_{i} \frac{z_{i}}{n_{s}\left[K_{i}-1\right]+1}=1 \\
& \sum_{i} w_{i}=\sum \frac{Z_{i} K_{i}}{n_{s}\left[K_{i}-1\right]+1}=1
\end{aligned}
$$

Using Newton-Raphson iteration technique, Eqs. (28) and (29) is calculated to determine the phase molar fractions, $n_{L}$ and $n_{S}$, and the molar compositions $x_{i}$ and $w_{i}$ for the phases.

\subsection{Quantity of Wax Precipitated}

The amount of wax precipitated at any temperature can be obtained from Equation (30) as:

$$
\begin{gathered}
\text { Wax weight }(\%)=\frac{\text { totalprecipitatedmass }}{\text { massof crudeoil }} \times 100 \%= \\
\frac{\sum\left(M_{w i} x_{i}^{S}\left(\frac{S}{F}\right)\right)}{\sum\left(M_{w i} Z_{i}\right)} \times 100
\end{gathered}
$$

\section{Results Discussion}

Experimental data obtained from three synthetic mixtures of different normal paraffin compositions were used in the model validation. Table 1 shows the specifications of these synthetic mixtures.

Table 1. Oil Mixture Composition Used, Pauly et al. [27].

\begin{tabular}{llll}
\hline \multirow{2}{*}{$\begin{array}{l}\text { Feed } \\
\text { composition }\end{array}$} & Mass \% & & \\
\cline { 2 - 4 } n-C10 & Mixture A & Mixture B & Mixture C \\
n-C18 & 0 & 47.76 & 65.02 \\
n-C19 & 0 & 7.17 & 3.55 \\
n-C20 & 10.30 & 6.41 & 3.55 \\
n-C21 & 7.40 & 5.74 & 3.56 \\
n-C22 & 5.29 & 5.16 & 3.55 \\
n-C23 & 3.79 & 4.63 & 3.53 \\
n-C24 & 2.70 & 4.16 & 3.51 \\
n-C25 & 1.93 & 3.72 & 3.48 \\
n-C26 & 1.37 & 3.32 & 3.45 \\
n-C27 & 0.97 & 2.97 & 3.41 \\
n-C28 & 0.69 & 2.64 & 3.39 \\
n-C29 & 0.49 & 2.08 & 0 \\
n-C30 & 0.35 & 1.85 & 0 \\
\hline
\end{tabular}

Figure 1shows the plot of the feed mole against molecular weight for the given oil mixtures used in the modelling while Figure 2 shows the result of characterizing the wax phase using weight fraction of component in the solid phase $w t_{i}$ for given oil mixtures.

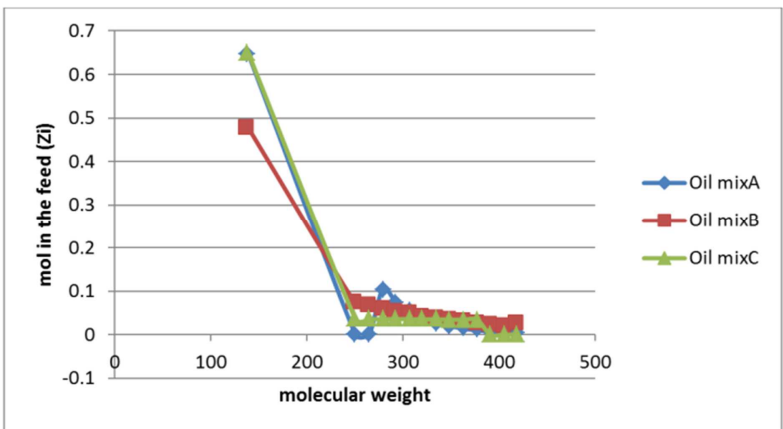

Figure 1. Feed moles vs molecular weight.

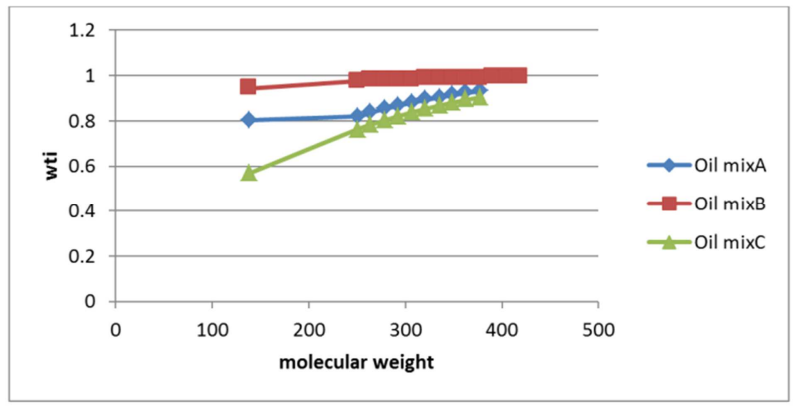

Figure 2. Solid phase weight fraction vs molecular weight.

The calculated wax appearance temperature for the oil mixtures is shown in Figures 3 and 4. The Figures indicates that the predictions obtained by this model are in good conformity with the actual behaviour of petroleum mixtures. From Figures 3 and 4, it is observed that solid wax begins to 
precipitate once the temperature reaches the wax appearance temperature. With further temperature decrease, more wax will precipitate.

The wax appearance temperature predicted for the oil mixtures are equally given in Table 2 . When judged with experimental determined wax appearance temperature, it was in very close conformity with the experimental data. This close conformity is more evident in Table 3 that shows the error percentage of WATs.

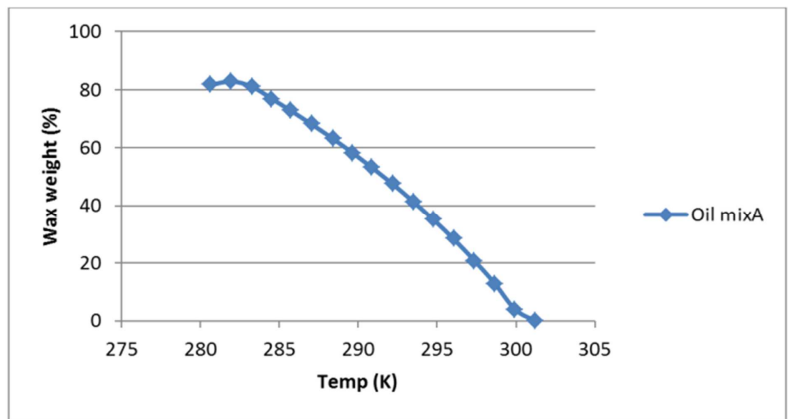

Figure 3. Calculated wax appearance temperature curve for oil mixA.

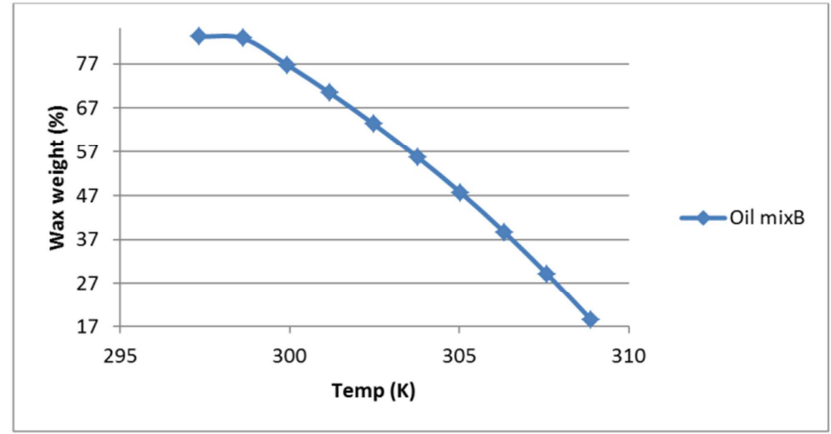

Figure 4. Calculated wax appearance temperature curve for oil mixB.

Table 2. Comparison of the Predicted WAT for Models.

\begin{tabular}{llll}
\hline Oil type & $\begin{array}{l}\text { Experimental } \\
\text { result (K) }\end{array}$ & $\begin{array}{l}\text { Pauly et al. } \\
\text { (K) }\end{array}$ & This work (K) \\
\hline Oil MixA & 294.15 & 302.15 & 301.21 \\
Oil MixB & 300.15 & 310.15 & 308.91 \\
Oil MixC & 298.15 & 302.15 & 300.38 \\
\hline
\end{tabular}

Table 3. The error percent of the WAT for the models.

\begin{tabular}{lll}
\hline Oil type & Pauly et al. (K) & This work (K) \\
\hline Oil MixA & 2.72 & 2.40 \\
Oil MixB & 3.33 & 2.92 \\
Oil MixC & 1.34 & 0.75 \\
\hline
\end{tabular}

\section{Conclusions}

Based on the result obtained from this study using thermodynamic relation, a model that predicts a more conservative and accurate result for WAT and the amount of solid wax has been established. Improving on the prediction of wax appearance temperature (WAT) and the amount of solid wax formed below the cloud point temperature is of great boost to the custody transfer operation. Accurate and early prediction of wax precipitation by this study will assist in reducing the millions of dollars lost by the oil industries through a more robust facility design, field development planning and adequate petroleum production planning.

\section{Acknowledgements}

The authors are grateful to the Federal University of Technology Owerri for supporting this research through their award of $\mathrm{PhD}$ fellowship.

\section{References}

[1] I. M. Onyejekwe. "Prediction of Wax Formation in Petroleum Fluid Using Thermodynamic Relations.” Ph. D. thesis, Federal University of Technology Owerri, Nigeria, 2018.

[2] K. W. Won. "Continuous thermodynamics for solid-liquid equilibria: Wax formation from heavy hydrocarbon mixtures." Fluid Phase Equilibria, vol. 33, pp. 265-279, 1986.

[3] K. W. Won. "Thermodynamic calculation of cloud point temperatures and wax phase compositions of refined hydrocarbon mixtures." Fluid Phase Equilibria, vol. 53, pp. 377-396, 1989.

[4] J. H. Hansen., Aa. Fredenslud., K. S. Pedersen., \& H. P. Ronningsen. "Thermodynamic model for predicting wax formation in crude oils." Vol. 34 (12), pp. 1937-1942. 1988.

[5] R. G. Snyder., M. C. Goh., V. J. Srivatsavaoy., H. L. Stauss., \& D. L. Dorest. "Measurement of the growth kinetics ofmicrodomainsin binary n-alkane solid solutions by infrared spectroscopy". J. phys. Chem, vol. 96 (24), pp. 10008-10019, 1992.

[6] R. G. Snyder., G. Conti., H. L. Strauss \& D. L. Dorest. "Thermally induced mixing in partially microphase segregated binary n-alkane crystals." Journal of phys. chem., vol. 97 (28), pp. 7342-7350, 1993.

[7] R. G. Snyder., V. J. Srivatsavoy., D. A. Cates., H. L. Strauss., J. W. White., \& D. L. Dorest. "Hydrogen deuterium isotope effects on microphase separation in unstable crystalline mixtures of binary n-alkanes". Journal of phys. chem., vol. 98 (2), pp. 674-684, 1994.

[8] W. B. Pedersen., A. B. Hansen., E. Larsen., A. B. Nielsen., \& H. P. Ronningsen. "Wax precipitation from North Sea crude oils. 2. Solid-phase content as function of temperature determined by pulsed NMR". Energy \& Fuels, vol. 5 (6), pp. 908-913, 1991.

[9] R. M. Jorda. "Paraffin deposition and prevention in oil Wells." Journal of petroleum technology, pp. 1605-1612, 1996.

[10] O. Bello., S. Fasesan., C. Teodoriu., \& K. Reinicke.” An evaluation of the performance of selected wax inhibitors on paraffin deposition of Nigeria crude oils." Pet SciTechnol, vol. 24, pp. 195-206, 2006.

[11] B. F. Towler., A. K. Chejara., \& S. Mokhatab,” Experimental investigations of ultrasonic waves effects on wax deposition during crude oil production.” In: SPE-109505 presented at SPE Annual Technical Conference and Exhibition. Anaheim, California, 2007, pp. 11-14. 
[12] G. Anand., \& S. Anirbid."Need of flow assurance for crude oil pipelines: A review." International Journal of Multidisplinary Sciences and Engineering, vol. 6 (2), Feb. 2015.

[13] H. Ahmed., \& M. A. Raines. "Paraffin Deposition from Crude Oils: Comparison of Laboratory Results to Field Data," SPE 38776. Presented at SPE Annual Technical Conference and Exhibition held in San Antonio Texas, 1997, pp. 5-8.

[14] P. A. Bern., V. R. Winthers., \& J. R. Cairns. "Wax deposition in crude oil pipelines." A paper presented at European offshore petroleum conference and exhibition, London, 1980, pp. 571-578.

[15] R. M. Jorda. "Paraffin deposition and prevention in oil Wells." $J P T$, pp. 1605-1619, 2009.

[16] A. R. SolaimanyNazar., B. Dabir., \& M. R. Islam.” A multisolid phase thermodynamic model for predicting wax precipitation in petroleum mixtures." Energy Sources, vol. 27, pp. 173-184, 2005.

[17] C. Wuhua and Z. Zongchang. "Thermodynamic modeling of wax precipitation in crude oils." Chin J ChemEng, vol. 14, pp. 685-689, 2006.

[18] B. Edmonds., T. Moorwood., R. Szezepanski., X. Zhang. "Simulating wax deposition in pipelines for flow assurance." Energy Fuels, vol. 22, 729-741, 2008.

[19] E. Ramirez-Jaramillo., C. Lira-Galeana., \& O. Manero. "Numerical simulation of wax deposition in oil pipeline systems.” Petrol SciTechnol, vol. 19, pp. 143-156, 2001.

[20] E. Ramirez-Jaramillo., C. Lira-Galeana., \& O. Manero. "Numerical simulation of wax deposition in oil pipeline systems." Petrol SciTechnol, vol. 22, pp. 821-861, 2004.
[21] J. M. Prausnitz., R. N. Lichtenthaler., \& E. G. Azevedo. Molecular thermodynamic of fluid-phase equilibria. PrenticeHall, Englewood Cliffs, NJ, 1999.

[22] R. Banki and A. Firoozabadi. "Modeling of wax deposition in pipelines from irreversible thermodynamics," A paper SPE 77571, Presented at Annual Technical Conference and Exhibition, San Antonia, 2002.

[23] M. Halsten., B. K. Arvoh., L. Amundsen., \& R. Hoffmann. "Online estimation of wax deposition thickness in singlephase sub-sea pipelines based on acoustic chemometrics: a feasibility study." Fuel, vol. 105, pp. 718-727, 2013.

[24] K. S. Pedersen. "Prediction of cloud point temperatures and amount of wax precipitation."SPE production and facilities, vol. 10 (1), pp. 46-49, 1995.

[25] X. Zhou and F. B. Thomas. "Modeling of solid precipitation from reservoir Fluid.” JCPT, vol. 35 (10), pp. 37-45, 1996.

[26] A. A. Sulaimon., G. K. Falade., \& W. DeLandro. "A proactive approach for predicting and preventing wax deposition in production tubing strings: A Niger Delta experience." $J$. petroleum and gas engineering, vol. 1 (2), pp. 26-36, 2010.

[27] J. Pauly., C. Dauphin., \& J. L. Daridon. "Liquid-solid equilibria in a decane + multi-paraffins system." Fluid Phase Equilibria, vol. 149, pp. 191-207, 1998.

[28] J. A. P. Coutinho., B. Edmonds., T. Moorwood., R. Szezepanski\& X. Zhang. "Reliable wax Prediction for Flow Assurance," SPE 78324 Presented at Aberdeen Scotland, 2002, pp. 1-11. 